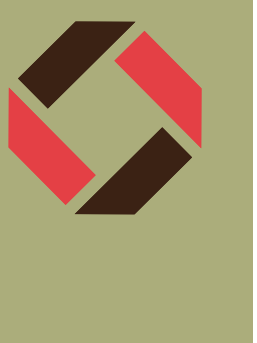

\section{Drexel hosts Philly Materials Day}

www.phillymaterials.org

\section{Steven Spurgeon}

$\mathbf{F}$ or a discipline that can be traced back to the construction of the pyramids and the forging of ancient bronze weapons, materials science is still a largely unknown branch of science. Last year, when the US Public Broadcasting Service (PBS) decided to air the NOVA series titled "Making Stuff," faculty at Drexel University in Philadelphia saw an opportunity to draw attention to the study of solids. In collaboration with the University of Pennsylvania (Penn) and the local PBS affiliate WHYY, the Drexel Department of Materials Science and Engineering hosted the first-ever "Philly Materials Science and Engineering Day" in February 2011, building on interest generated by the NOVA special. The event, now in its second year, seeks to engage and inform the public through hands-on demonstrations, lectures, and

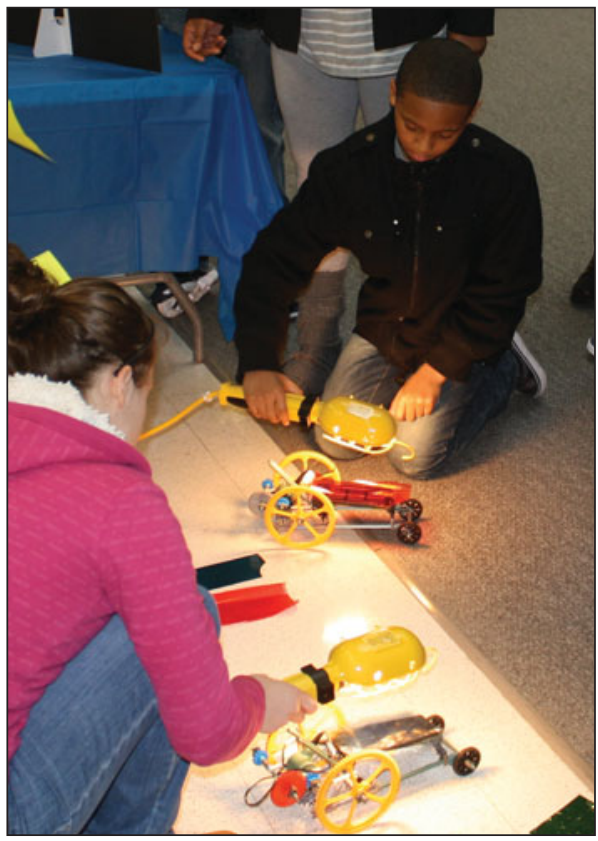

Photos by Andrew Marx tours of laboratory facilities. The event has drawn hundreds of attendees, promoted scientific awareness, and spotlighted universities in Philadelphia.

In February of this year more than 1300 visitors arrived at the Bossone Research Enterprise Center on Drexel's campus for the event. They were greeted with demonstrations and lectures by distinguished scientists as well as feasting on music and food. Children mixed polyvinyl alcohol and sodium tetraborate to create bubbling slime. Graduate students handed out sweet ice cream treats blastchilled with liquid nitrogen. And towering above the action was a 100 -foot-tall balloon carbon nanotube. The excitement in the air was palpable, stoked by the booming English brogue of Drexel Materials' Associate Department Head Richard Knight, the day's designated emcee.

Asked about his motivation, Knight said that it was an excellent opportunity to spark interest in a field he loves. "The age-old problem we find is that people have no concept of what materials science and engineering is, but once you explain and show people, they have a better idea. They begin to realize then that everything is made of materials and there's a reason why we choose the materials we do." This sentiment guided the organizers, who tried to concoct an appealing mix of education and fun for a diverse crowd of children and adults.

Throughout the day, graduate students held demonstrations showcasing mechanical properties, photovoltaics, glassy transitions, and biomaterials, among others. The university also hosted lectures, a musical performance by local "hip-hop scientist" Grand Hank, and a questionand-answer panel with faculty.

University of Pennsylvania Professor Karen Winey, who participated in the panel, said, "I feel very strongly that [Philly Materials Day] is good for our city. It was also good for our graduate students and undergraduates who were involved in demonstrations. Their enthusiasm is contagious."

Winey said that outreach events like Materials Day demystify science, making it accessible and exciting for the public. Moreover, she feels that scientists are obligated to make their work understandable to the greater community. The event forces students and professors to think creatively and teaches them to simplify complex ideas. In the process students often clarify their own understanding,

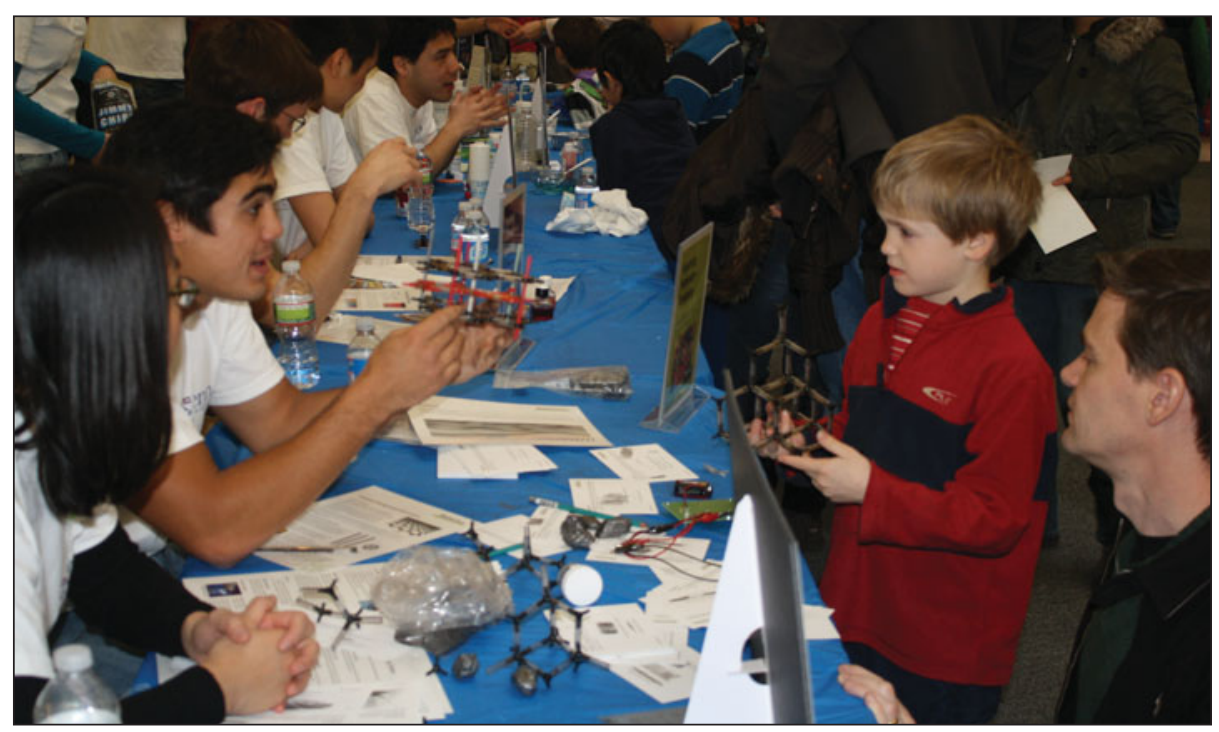




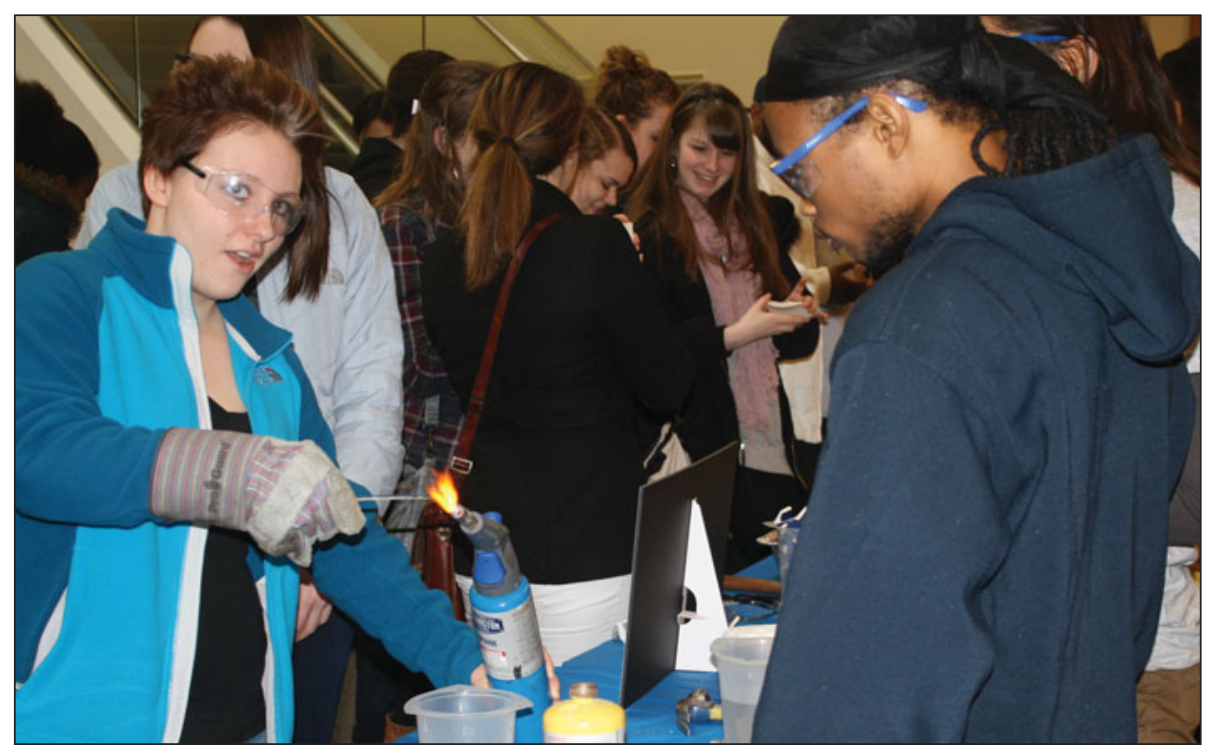

making them more effective researchers.

Describing liquid-crystal phase transitions to an audience spanning 8 to 80 years old can be a challenge, said graduate student Cole Smith. "You're trying to explain crystal structure to someone who doesn't know what an atom is." To make the subject more relatable, Smith and other students tried to connect abstract concepts to everyday things. For example, a focused ion beam used for micromachining was described as an atomicscale sandblaster. Student Chris Barr had a similar experience and quickly realized he had to adjust the complexity of his "physics of sporting equipment" demo for different audiences.

Despite these challenges, attracting volunteers was not difficult-in fact, many graduate students jumped at the opportunity to share their passions with someone outside the lab. "It's nice to have people come see what I do and be thrilled about it for a change," said Smith.

Undergraduate students were also lured in by the promise of community service credits and many had to be turned away. Professors were motivated by similar benefits, since outreach and community involvement are critical components of National Science Foundation (NSF) and other funding agency grant proposals.

Hosting a multi-university event with dozens of demonstrations re- quires months of planning. According to Dorilona Rose, operations manager in Drexel's Materials Department, the greatest difficulty was advertising the event. The department tried a mix of traditional and social media. "We were worried about how to get people to come... [and] we would advertise on buildings and post in calendars and bulletins. We tried to drum up support on our Facebook page and bought a Facebook ad. The College of Engineering also posted on their Facebook and Twitter pages."

Momentum and media coverage built up for last year's event carried over to this one, thanks in part to the support of PBS, NSF, and the Department of Energy. The latter two provided $\$ 6,000$ in seed money to participating "outreach coalitions" in 2011, which helped lay the groundwork for this year's event. Alumni and local companies were also invited to sponsor events.

Keeping activities fresh and interesting was another challenge for the organizers, who then turned to help from the local science museum, The Franklin Institute. Jayatri Das, The Franklin Institute senior exhibit and program developer, said that the museum first became interested when PBS started promoting "Making Stuff." Once Penn and Drexel started organizing Materials Day, it seemed natural to have the museum participate. Das said that the museum is able to draw on its talented

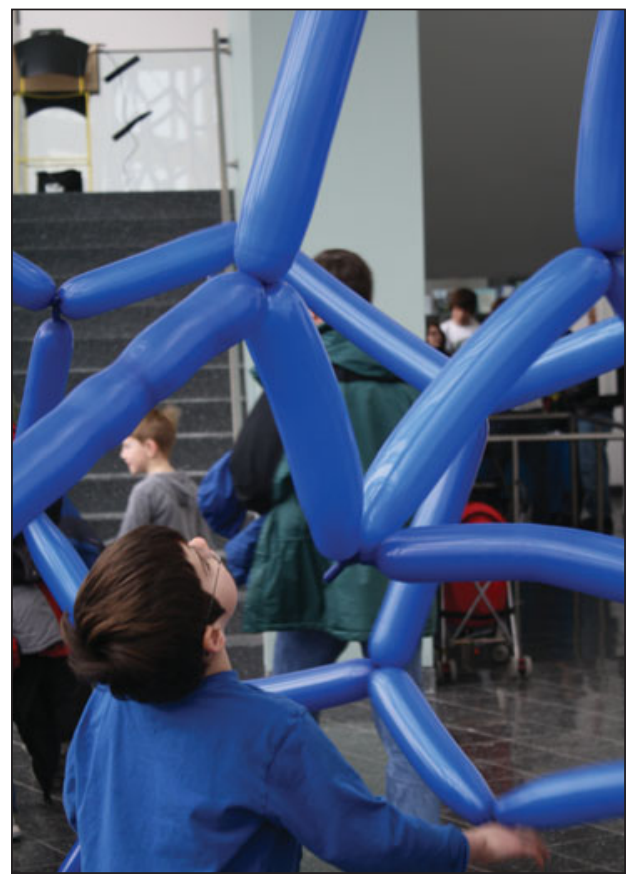

staff and experience from other outreach events to develop engaging and targeted exhibits. The event also helped establish a network with Drexel and Penn, which made it much easier to host the Philadelphia Science Festival later in the year.

Das emphasized the many benefits to outreach, ranging from increased publicity to stronger applications for federal funding. She said that museums can serve as an efficient catalyst for such events, complementing researchers' content with public engagement expertise. She encourages potential universities to seek out members of the Nanoscale Informal Science Education (NISE) Network when planning such events. More information can be found at the organization's website (www.nisenet.org/rise/).

Asked what next year has in store, Rose said that Drexel plans to enlist the help of the nearby Academy of Natural Sciences in Philadelphia and expand on the partnership with The Franklin Institute. Materials science offers the unique convergence of chemistry, physics, and engineering needed to address challenging issues in energy, pollution, and medicine. Citywide partnerships between universities, museums, and companies can harness the collective talent of the scientific community to engage the public about these challenges. 


\section{Become an MRS Gongressional Science and Engineering Fellow!}

\section{Help improve the interface between science and legislative decision-making.}

\section{Advocate for policies that will facilitate the discoveries of the future.}

\section{Play a crucial role as you educate the public about the benefits of science.}

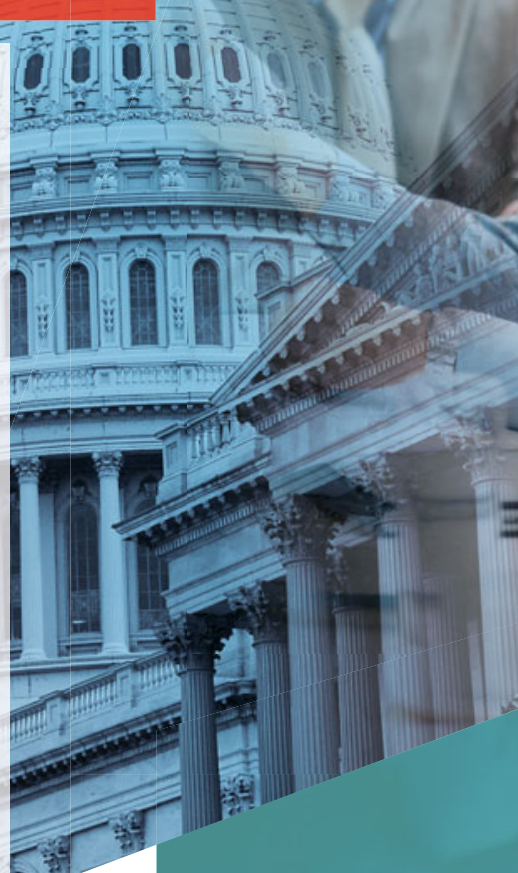

The MRS Congressional Science and Engineering Fellowship Program is an invaluable experience, but don't just take our word for it. Our past Congressional Fellows explain it best!

"Academia taught me how to think, but the MRS Congressional Fellowship taught me how to get things done. Never have I had such leverage, such opportunities to comingle with dignitaries, to structure agreements and broker deals, as I did in that year. I learned how to navigate past armies of secretaries shielding a VIP, enlist military support for a project, take a rough idea and make it law, to fashion an event into a sound bite and then watch it propagate across the news. I learned to take data and present it in such a way that it gravitated, almost of its own accord, all the way up to the Vice President of the United States. These are skills anyone, who is going anywhere, can use."

Decisions made by Congress, regulatory agencies and science is conducted. By keeping decision-makers well informed on the current affairs of the scientific community, MRS Congressional Science and Engineering Fellows ensure the right choices are being made. Now's your time to make a difference!

The Materials Research Society offers material scientists two exciting opportunities to participate in, and contribute to, the federal policymaking process, while learning firsthand about the intersection of science and policy.

Merrilea Mayo Founder, Mayo Enterprises, LLC.

MRS Congressional Fellow 1998-1999

Office of Senator Lieberman

During your year as a Fellow you will:

- contribute widely to the effective use of materials science knowledge in government

- broaden awareness about the value of scientist- and engineer-government interaction among society members and within government

- have significant freedom to follow specific topics and issues that interest you

"At the end of the fellowship year I found that I was enjoying "doing" science policy more than just teaching about it, and I ended up staying on in Rep. Honda's office as a member of the staff where I have remained for over a decade. I would not have had that opportunity without the Congressional Fellowship. I encourage anyone who wonders about how federal policies are developed or wants to have a greater role in that process to apply to be a Congressional Fellow."

Eric Werwa Legislative Director, Congressman Mike Honda

MRS Congressional Fellow 2001-2002

Office of Congressman Mike Honda

To learn more about the MRS Congressional Science and Engineering Fellowship Program and how you can apply, visit www.mrs.org/congressional-fellows.

Applications for the 2013-2014 MRS Congressional Science and Engineering Fellowship Program will be posted on the MRS website in September 2012. Deadline for submission is January 4, 2013. 